\title{
On Hydraulic Transmission Teaching
}

\author{
Huanyun Wang ${ }^{1}$ Huandong Wang ${ }^{2}$ \\ ${ }^{1}$ Department of Mechanical Engineering, Cangzhou Normal University, Cangzhou \\ 061001, Hebei, China \\ ${ }^{2}$ Department of Computer Science, Hebei Engineering and Technical College, Cangzhou \\ 061001, Hebei, China
}

\begin{abstract}
Hydraulic Transmission is an important professional foundation course in majors such as machinery, transportation, and automation, in which deep theory and strong practice are closely related. This paper analyzes the characteristics of the course and students' learning problems, and summarizes some teaching methods based on teaching practice in order to provide some references for colleagues.
\end{abstract}

Keywords:hydraulic transmission; course; training target; teaching methods.

\section{Introduction}

Hydraulic transmission is an important professional foundation course based on fluid mechanics. This course is theoretical, systematic and logical, as well as very practical. Students are lack of perceptual knowledge on hydraulic transmission, so quite a few of students think it is difficult to learn. In order to solve this problem, the teacher should use a variety of teaching methods in the classroom to foster students' interest in learning. To make students understand and grasp the course content easily, the author has combined the applied talents training goal with and course characteristics and used some teaching methods in teaching practice, which has had good effect.

\section{Use case guidance and process lead to train and motivate students' in- terest in study}

Interest is the best teacher. Hydraulic Transmission is new to most of the students concerned, so they don't have any concept about it. How to make the students accept Hydraulic Transmission step by step? On the one hand, grasp the keyword "transmission" and make the student to recall the transmission types studied such as gear drive (transmission), chain (bicycle), shaft drive (automobile drive shaft), tape drive (farm tricycle). At this time, students will realize that hydraulic transmission should belong to "drive" and has the common characteristic of transmission. On the other hand, make students understand that drive is a mechanism and it is a device between a dynamic mechanism and actuator and think if hydraulic transmission is also like this? At this moment explain the differences to students between hydraulic transmission and other types of transmissions. Hydraulic Transmission is an independent discipline because it has all devices of power, drive and actuator and introduces hydraulic system.

To master the five system compositions of hydraulic drive is not only the foundation to learn the subsequent course, but also the premise to understand the hydraulic system. Therefore, teachers may analyzes the working principle of the hydraulic jack 
first which students are most familiar with. And then, compare its working principle with the working principle of hydraulic grinding machine and introduce the hydraulic drive parts and their functions one by one. In this way students can master hydraulic system components, understand the function of each part, deepen the understanding of the hydraulic transmission and improve the learning interest. This method can be used in many cases. For example, introduce its characteristics of light quality and small motion inertia by the manufacturing material of hydraulic components; its characteristic of realizing the automation easily by application of stroke switch and pressure relay; its characteristic of not realizing strict transmission ratio by liquid compressibility, etc. Using this method can make the students master the characteristics of hydraulic transmission and can relate them to specific materials or physical characteristics so as to achieve the purpose of permanent memory.

3. Optimize the teaching content, give priority to practical theory, and highlight the practical and advanced nature.

Adhere to the principle of "necessary and sufficient", cut complicated theoretical elaboration and formula deduction and pay attention to increase the actual application cases in the working environment $^{[1]}$. For instance, the law of conservation of energy -- Bernoulli's equation in liquid dynamics may not to be deduced and the emphasis should be put on the physical and geometric meaning of Bernoulli's equation, namely, the transformation relationship among the three energies. To make students learn to use the equation to analyze or solve problems, the key is to select the numerical values in the formula, namely, potential value (taken in the horizontal plane); Pressure energy value (taken in boundary section to reduce the unknown); Kinetic energy value (taken in the free surface of large container as zero). To combine with exercises to explain one or two examples is a good method to shorten the teaching time and make students learn to analyze and solve problems so as to arouse the students' learning initiation. Another instance is to add the actual selection, common fault diagnosis and elimination method in the pump, cylinder, valve and other major components as well as basic circuit chapters and increase the typical hydraulic drive system examples in order to make students learn professional knowledge closer to the application needs. To ensure that teaching materials keep pace with technology progress in the related industries teachers should combine the development of hydraulic and pneumatic technologies, increase the introduction of new equipment, new technology, new products and their development direction. In this way we can make the students contact and know the advanced technology in the field of this course during the period of school, lay good foundation for the employment, and realize the integration of professional teaching basic and progressiveness.

\section{Highlight professional skills train- ing and realize the theory teaching and practice teaching organically.}

Pay attention to construct the practice teaching system adapted to the theory teaching system and overcome the disadvantages of only paying attention to theory teaching and ignoring the practice teaching in the past in order to greatly increase the proportion of practice teaching in the course ${ }^{[2]}$. Arrange sufficient practice teaching content and put forward the specific requirements of 
the cultivation of the students' capability and the corresponding measures such as the training contents, training purpose, practical tools, training steps, training results, practice instruction to fill in etc. Through the training, students can deepen understanding of knowledge, enhance the ability and professional skills and reach the high unity of theory knowledge and professional skill training. At the same time the practice teaching can cultivate students' innovative consciousness and help them to improve the innovative practice ability.

\section{Use varied teaching methods to im- prove teaching effect}

As the saying goes, teaching amorphous method is inspiring. As long as it can stimulate students' interest in learning and raise the enthusiasm of the students' learning it is a good method.

\subsection{Module teaching}

Most of the hydraulic transmission materials adopt the arrangement sequence "hydraulic drive overview--fluid mechanics--dynamic components-actuating components--control components--auxiliary components-hydraulic system--experiment ". But in every chapter the introduction is in detail but in a mess. Students have to tax their mind and strength to master the content and the learning effect is poor. In view of this situation the author uses module teaching to gather parts into a whole. From the five parts of hydraulic system to the basic circuit of hydraulic drive in each chapter we can teach students to grasp the details in accordance with the unified mode.

\subsection{Project teaching method}

Emphasize practice while learning. in some content such as the basic circuit use task-driving teaching method. Make clear each teaching training objectives, teaching content, teaching training methods, and teaching training tasks so that each teaching training task becomes a relatively complete teaching unit to keep the students motivated.

\subsection{Case method}

In case method much attention should be paid to the selection of the cases ${ }^{[3]}$. For instance, give priority to production workshop real case in the typical hydraulic system. Through case study students are not only familiar with some typical working process of hydraulic drive but also arouse their study enthusiasm.

\subsection{Analogy method}

In the teaching process of overflow valve, relief valve and sequence valve, we can use analogy method to compare the function symbols and structure theory so as to understand the differences and relationship in function and structure among the three kinds of valves from every aspect to improve the teaching effect.

\section{Combine teaching and research and establish interest groups or innova- tion team to cultivate students' comprehensive ability.}

Students interested in hydraulic can establish interest groups ${ }^{[4]}$. Everyone can exchange learning comments regularly or irregularly under the organization of the teacher, discuss system design or fault diagnosis, and even can be involved in the actual research project. Interest groups play the role of a learning example. On the one hand, they can improve their own level through discussion and learning from each other. 
On the other hand they will help other students progress together.

\section{Conclusion}

Through several years of teaching practice the author finds that using these methods can improve the students' learning interest, improve the teaching quality and achieve significant teaching effect. Inevitably there are some deficiencies and shortcomings in the teaching process, but Hydraulic Transmission teaching reform will be more fruitful through unremitting exploration and practice.

\section{References}

[1] Ruijie Wang et al.. The Practice and
Realization on Education Innovation of Course Hydrauolic Drive . Journal of Agricultural Mechanization Research. 2004,9: 248-250.

[2] Shuhai Chen. The Research and Practice of Teaching Innovation of the Course Hydraulic ransmission. Chinese Hydraulics \& Pneumatics. 2008,5: 57-58.

[3] Wenxuan Zeng. The Reform Practice and Exploration of Hydraulic and Pneumatic Control Course. Journal of wuxi institute of technology. 2011,10: 62-63.

[4] Baochen Ren et al.. Teaching reform and exploration of hydraulic and pneumatic transmission technology courese for college.Chinese Hydraulics \& Pneumatics. 2011,3: 41-43. 